\title{
Female genital mutilation/cutting in Sierra Leone: are educated women intending to circumcise their daughters?
}

\author{
Edward Kwabena Ameyaw ${ }^{1 *}$ D, Justice Kanor Tetteh ${ }^{2} \mathbb{D}$, Ebenezer Kwesi Armah-Ansah², Kofi Aduo-Adjei ${ }^{3}$ and
} Aisha Sena-Iddrisu ${ }^{4}$

\begin{abstract}
Background: Female genital mutilation/cutting (FGM/C) has been recognized as a gross violation of human rights of girls and women. This is well established in numerous international legal instruments. It forms part of the initiation ceremony that confers womanhood in Sierra Leone. Girls and women who are subjected to this practice are considered to be ready for marriage by their parents and communities and are rewarded with celebrations, gifts, and public recognition. Following this, we examined the relationship between education and women's FGM/C intention for their daughters in Sierra Leone.

Methods: We used cross-sectional data from the women's file of the 2013 Sierra Leone Demographic and Health Survey (SLDHS) to explore the influence of education on FGM/C intention among women in the reproductive age (15-49). A sample of 6543 women were included in the study. Our analysis involved descriptive computation of education and FGM/C intention. This was followed by a two-level multilevel analysis. Fixed effect results were reported as Odds Ratios and Adjusted Odds Ratios with their respective credible intervals (Crls) whilst results of the random effects were presented as variance partition coefficients and median odds ratios.

Results: Our findings showed that women who had no formal education were more likely to intend to circumcise their daughters $[\mathrm{aOR}=4.3, \mathrm{Crl}=2.4-8.0]$. Among the covariates, women aged 20-24 [aOR $=2.3, \mathrm{Crl}=1.5-3.4]$ were more likely to intend to circumcise their daughters compared to women between 45 and 49 years old. Poorest women were more likely to report intention of circumcising their daughters in the future compared with the richest $[\mathrm{aOR}=2.1, \mathrm{Crl}=1.3-3.2]$. We noted that, $63.3 \%$ of $\mathrm{FGM} / \mathrm{C}$ intention in Sierra Leone is attributable to contextual factors.

Conclusion: FGM/C intention is more common among women with no education, younger women as well as women in the lowest wealth category. We recommend segmented female-child educational and pro-poor policies that target uneducated women in Sierra Leone. The study further suggests that interventions to end FGM/ $C$ need to focus on broader contextual and social norms in Sierra Leone.
\end{abstract}

Keywords: Female genital mutilation, Female genital cutting, Circumcision, Education, Sierra Leone

\footnotetext{
* Correspondence: edmeyaw19@gmail.com

'The Australian Centre for Public and Population Health Research, Faculty of Health, University of Technology Sydney, Sydney, NSW, Australia

Full list of author information is available at the end of the article
}

(c) The Author(s). 2020 Open Access This article is licensed under a Creative Commons Attribution 4.0 International License, which permits use, sharing, adaptation, distribution and reproduction in any medium or format, as long as you give appropriate credit to the original author(s) and the source, provide a link to the Creative Commons licence, and indicate if changes were made. The images or other third party material in this article are included in the article's Creative Commons licence, unless indicated otherwise in a credit line to the material. If material is not included in the article's Creative Commons licence and your intended use is not permitted by statutory regulation or exceeds the permitted use, you will need to obtain permission directly from the copyright holder. To view a copy of this licence, visit http://creativecommons.org/licenses/by/4.0/ The Creative Commons Public Domain Dedication waiver (http://creativecommons.org/publicdomain/zero/1.0/) applies to the data made available in this article, unless otherwise stated in a credit line to the data. 


\section{Background}

The fifth Sustainable Development Goal seeks to abolish all harmful practices including female genital mutilation/ cutting (FGM/C) by the year 2030 [1]. FGM/C is a gross violation of human rights [2]. The 2018 World Bank's Compendium of International and National Legal Frameworks on $\mathrm{FGM} / \mathrm{C}$ indicate that about 60 countries have adopted anti FGM/C laws [3]. FGM/C is a harmful cultural and traditional practice in Sierra Leone, other countries in sub-Saharan African, Asia, Middle East and some communities in South America [2, 4, 5]. It has also been reported in some western countries such as Australia, New Zealand, Canada, and the United Kingdom [5]. FGM/C refers to all procedures involving total or partial removal of the external parts of female genitalia or any other injury to the genital organ $[6,7]$. The WHO has identified four main types of FGM/C. This is based on the severity of injury to the genitalia and may not involve the removal of flesh, such as pricking, piercing or scraping (type 4), to infibulation, in which the vaginal opening is narrowed by cutting and repositioning the labia to create a partial cover (type 3) [8]. Type 1 involves the partial removal of the clitoral glans and/or clitoral hood whilst type 2 constitutes the partial or complete elimination of clitoral glans and labia minora with/without eliminating the labia majora [7, 9]. FGM/C is usually carried out on young females between infancy and 15 years [8]. FGM/C threatens the health and well-being of millions of girls, women and their children globally [1].

More than 200 million girls and women alive today have been cut in Africa, the Middle East and Asia [10]. In Africa, an estimated 92 million girls 10 years and older have undergone the practice [8]. Victims may die during the procedure due to haemorrhage or septic shock [11], or experience considerable physical, psychological and sexual complications [12-15]. Surveys conducted across Africa, the Middle East, and Southeast Asia document $\mathrm{FGM} / \mathrm{C}$ prevalence rates ranging from 1\% (Uganda, Cameroon) to more than 95\% (Guinea and Somalia) [16]. Although some sub-Saharan African (SSA) communities believe that the procedure ensures virginity before marriage and keeps one's sexual organs clean [17], researchers in Kenya and Nigeria observed no association between FGM/C and outcomes for sexual behaviour [18]. Social pressure has been cited as one of the principal reasons for FGM/C $[7,19,20]$. Others also consider it as removing "unclean" parts of the girl's body which is essential for maintaining femininity [21] and enhancing marriage prospects [22, 23]. However, no scientific evidence support its medical benefits [24].

In the last decade, criminalization of $\mathrm{FGM} / \mathrm{C}$ is gaining momentum in law including penal codes, and domestic violence acts [3]. Of the $29 \mathrm{FGM} / \mathrm{C}$ prevalent countries in Africa, 24 governments have enacted laws against the practice [25]. For example, countries such as Ghana, Burkina Faso, Ivory Coast, Senegal, Djibouti, and Togo have banned FGM/C [2]. In line with this, a number of professional associations including International Federation of Obstetricians and Gynaecologists as well as the International Confederation of Midwives denounce the practice and call on all professional associations to condemn it [25].

Consistent negative association has been reported between women's education, FGM/C intention and its perpetration [26-30]. The common pathways for the negative association include the fact that education enlightens women to appreciate the consequences of FGM/C on females' sexual and reproductive health [28] including mental health implications [31]. Education in effect empowers women to oppose all forms of violence against women and protect their children from experiencing FGM/C and abuse of all forms [30, 32]. Meanwhile, Hayford et al. [33] observed that daughters of women with primary or higher education experienced FGM/C in Burkina Faso, Cote d'voire, Guinea and Mali.

In Sierra Leone, FGM/C forms part of an initiation ceremony which confers womanhood, locally termed as 'Bondo Bush.' The ceremony is conducted secretly to usher girls into womanhood [34].

Girls and women who are subjected to FGM/C are perceived to be well trained, ready for marriage and are rewarded with celebrations, gifts, and public recognition in Sierra Leone [35]. It is believed that the physical pain endured helps to create a life-long fellowship among girls who are jointly initiated [34]. Sierra Leone is a member of several international human rights conventions which recognise FGM/C as a violation of human rights [36]. However, there is no prohibition of FGM/C, or any explicit law against the practice in Sierra Leone [29, 36]. Although the 2007 Child Rights Act supersedes all other national laws related to children's rights, the FGM/C clause was removed from the final version during parliamentary debate [37].

In 2012, eight of the country's fourteen districts signed a Memorandum of Understanding (MoU) criminalizing FGM/C among children (in Western Area Rural, Western Area Urban, Bo, Kambia, Port Loko, Pujehun, Bonthe, and Kailahun) but the practice continues in many parts of these districts without any consequences for offenders $[2,36]$. The national statistics of Sierra Leone estimates that the prevalence of FGM/C slightly decreased from $91.3 \%$ in 2008 to $89.6 \%$ in 2013 [38]. The prevalence between females whose mothers have no education (95\%) and females whose mothers have at least secondary education (74.2\%) is higher in Sierra Leone than in neighbouring countries [34]. Sierra Leone is classified as a group one country with a prevalence of more than $80 \%$, according to the UNICEF classification [36]. 
Several studies have examined factors that influence FGM/C. Some have highlighted the decision makers for the practice [34], the forms and health complications [6]. Yet, little is known about the relationship between education and intention to circumcise daughters in Sierra Leone. This study, therefore, seeks to investigate the linkage between education and intention to circumcise one's daughter in the future. Findings and recommendations from the study will shape FGM/C policy formulation and evaluation of how best education can be utilised as a critical tool to end FGM/C in Sierra Leone and other $\mathrm{FGM} / \mathrm{C}$ prevalent countries.

\section{Methods}

\section{Data source}

Data for this study was obtained from the 2013 Sierra Leone Demographic and Health Survey (SLDHS) [38]. The 2013 SLDHS happens to be the second version of the Demographic and Health Survey following the first one in 2008. The survey intended to gather data for monitoring the population and health circumstances and to serve as a follow-up to the first survey. It captured information on female genital mutilation, fertility preferences, maternal and child health as well as sexual activity. It was implemented by the Statistics Sierra Leone (SSL) under the auspices of the Ministry of Health and Sanitation. The National Technical Committee and National Steering Committee provided technical and policy guidance for the conduct of the survey. Inner City Fund (ICF) International also offered technical assistance via the MEASURE DHS Program [38].

Sample for the survey was designed to generate dependable estimates for essential variables for the entire country in both rural and urban locations as well as across the four regions and the fourteen districts [38]. To ensure representation for all the aforementioned demarcations, the sample was stratified and selected in two stages. Primary Sampling Units (PSUs), also known as clusters were selected based on the list of enumeration areas (EAs) created in the preceding Population and Housing Census in the first stage [38]. The EAs offered the principal frame for selecting 435 clusters (158 from urban and 277 from rural) through probability proportional to their sizes. Excluded from the sampling frame were persons residing in collective housing units including hospitals, hotels and boarding schools [38]. Thirty (30) households were systematically selected from each of the clusters in the second stage. All eligible persons in the subsample of households participated in the study. This comprised women aged 15-49 and men aged 1559. Although, 17, 1323 eligible women (15-49 years) were identified in all, complete interviews were conducted with 16,658 and this culminated in a $97 \%$ response rate. Nearly half of these women had at least one daughter (46.7\%).
The three questionnaires used (household questionnaire, woman's questionnaire, and man's questionnaire) emerged from the models developed by the MEASURE DHS Program. However, the questionnaires were modified to fit the context of Sierra Leone [38].

\section{Study variables \\ Dependent variable}

Intention to circumcise daughter in the future was the dependent variable for the study. As part of the survey, the women were asked "Do you intend to have daughter(s) circumcised in future?" The corresponding responses were 'No' coded as 0 , 'Yes' coded as 1, and 'Don't Know', coded as 8 . To arrive at findings that reflect precision in thought and offer meaningful recommendations, women who responded 'Don't Know' were excluded from the study.

\section{Independent variable}

The principal independent variable was formal education. In the DHS survey, formal education is categorised into 'No Education', 'Primary Education', 'Secondary Education' and 'Higher Education'. Some socio-demographic characteristics of these women were included in the study to access their association with intention of the women to circumcise their daughters in the future. These are age, wealth, religion, region, residence, healthcare decision making, number of daughters already circumcised, frequency of reading newspaper, frequency of listening to radio and frequency of watching television (TV). Following the hierarchical structure of the datasets, all the variables were categorised into individual (education, age, wealth, religion, healthcare decision making, number of daughters, number of daughters circumcised, frequency of reading newspaper, frequency of listening to radio, frequency of watching television) and contextual (family head, region and residence) level factors. To ensure clarity, two of the variables were recoded. These are religionrecoded as 'Christian $=0$ ', 'Islam $=1$ ', 'Other $=2$ ' and number of daughters circumcised recoded as 'No $=0$ ', ' $1=1$ ', ' $2=2$ ', ' 3 or more $=3$.'

\section{Data analysis}

We carried out descriptive analysis as well as two-level multilevel analysis. At the descriptive level, we calculated women's education and the proportion of women who intended to circumcise their daughters in the future. Chi-square test was conducted in order to determine the socio-demographic variables that significantly relate with intention to circumcise daughter in the future. Due to the clustering and hierarchical nature of the datasets, these analyses were followed by the multilevel analysis conducted with the MLwinN command version 3.05 [39]. Prior to modelling, the dataset was ordered to account for the clustering nature of the survey. A total of 
four models were constructed with the first one being an empty model in order to ascertain the variance in FGM/ $\mathrm{C}$ intention at the contextual level (model 1). The second model comprised fixed effects at the individual level (model 2) whereas model three accounted for fixed effects at the contextual level (model 3). In the final model (model 4), fixed effects at the individual and contextual level were fitted. Results of the fixed effects were presented as odds ratios (ORs) and adjusted odds ratios $(\mathrm{aOR})$ together with their corresponding credible intervals $(95 \% \mathrm{Crl})$. Credible interval was based on the Bayesian statistical approach whereby probability allocation for association measurements are derived whilst 95\% credible intervals (95\% Crls) are used for summarisation. The $95 \%$ CrI implies the possibility of the parameter assuming a value in the specified range [40].

Variance partition coefficient (VPC), also referred to as intraclass correlation coefficient (ICC), and median odds ratio (MOR) were reported for the random effects [41, 42]. The VPC assesses the magnitude of variance in the likelihood of FGM/C intention that is explained by or attributable to contextual factors. The MOR, on the order hand, accounts for the contextual variance in terms of odds ratio and calculates the propensity of FGM/C intention that is explained by contextual factors. Multicollinearity was assessed with the variance inflation factor before the models were developed [43]. Sample weight was applied and the entire analysis was executed with Stata version 13.0.

\section{Ethics approval}

Ethical approval was granted by the Ministry of Health and Sanitation of Sierra Leone as well as the ethics committee of the DHS Program. During the survey, informed consent was sought from all participants. We applied for and were granted access to the dataset by the Measure DHS Program. The dataset is freely available through https://dhsprogram.com/data/available-datasets.cfm.

\section{Results}

\section{Descriptive results}

In Table 1, we presented the socio-demographic characteristics of the women. The same table presents women's FGM/C intention for daughters in the future by education and socio-demographic characteristics. We realised that at least seven out of ten women (74.8\%) had no formal education and only $1.4 \%$ had higher education. Nearly all the women without formal education (93.3\%) intended to circumcise their daughters whereas $32.4 \%$ of those with higher education intended to do the same. Women aged 25-29 (22.8\%) dominated whilst only 8.2\% were aged 45-49. FGM/C intention for daughter was high among those aged $40-44$ and $30-34$ as 90.4 and 90.2\% respectively revealed their intention to subject their daughters to FGM/C in the future. The proportion of poorest women $(22.7 \%)$ exceeded women in all other wealth categories especially when compared with the richest (15.2\%). A greater section of the poorest women reported FGM/C intention (94.9\%) and this did not vary much from women in other wealth quintiles.

A statistically significant difference existed between Muslims (92.8\%) and Christians (75.3\%) with FGM/C intention. A significant proportion of them jointly decided their healthcare with their partners (45.7\%), however, 91.3\% of those whose partners decided their healthcare had FGM/C intention. Nearly half of the women had one daughter (47.9\%), whilst $92.7 \%$ of those with four or more children intended to cut their daughters. Among women who did not have daughters, $14.2 \%$ revealed FGM/C intention. Most of them had not circumcised their daughters at the time of the survey (78.4\%).

Almost all the women who had already circumcised three or more daughters revealed their intention of circumcising other daughters in the future (98.9\%). Most of the women were not reading newspaper at all (95.7\%), not listening to radio at all (43.0\%) and not watching television at all (87.6\%). Almost all the women who were not reading newspaper at all $(91.3 \%)$, not listening to radio at all $(92.2 \%)$ and not watching television at all (91.9\%) reported FGM/C intention. Nine out of ten women in male-headed households intended to circumcise their daughters in the future (90.2\%). A significant proportion of them were residents of the Northern region $(38.4 \%)$ and $93.6 \%$ of women in the same region had FGM/C intention in the future. We realised that $74.6 \%$ were residing in rural locations and $93.5 \%$ of them reported FGM/C intention as illustrated in Table 1.

\section{Individual and contextual factors associated with FGM/C intention for daughter in the future}

As shown in Table 2, women who had no formal education were more than 4 times likely to report intention of subjecting their daughters to FGM/C in the future compared to those with higher education $[\mathrm{aOR}=4.3, \mathrm{CrI}=2.4-8.0]$. Compared with women aged 45-49, those aged 20-24 $[\mathrm{aOR}=2.3, \mathrm{CrI}=1.5-3.4]$ were more probable to indicate that they intended to circumcise their daughters in the future. Our findings showed that poorest women were more likely to report FGM/C intention for their daughters in the future compared with the richest $[\mathrm{aOR}=2.1, \mathrm{CrI}=1.3-3.2]$.

However, women who had none of their daughters circumcised were less likely to report FGM/C intention in the future compared to those who had three or more daughters circumcised $[\mathrm{aOR}=0.1, \quad \mathrm{CrI}=0.0-0.3]$. Intention to circumcise daughter in the future was two times likely among women in the Northern $[\mathrm{aOR}=2.2$, $\mathrm{CrI}=1.5-3.2]$, Eastern $[\mathrm{aOR}=2.1, \mathrm{CrI}=1.4-3.1]$ and Southern $[\mathrm{aOR}=2.1, \mathrm{CrI}=1.4-3.1]$ regions compared with those in the Western region. 
Table 1 Summary of socio-demographic characteristics of sample $(N=6543)$

\begin{tabular}{lllll}
\hline Variable & $\begin{array}{l}\text { Weighted } \\
\text { Frequency } \\
(\mathrm{n})\end{array}$ & $\begin{array}{l}\text { Percentage } \\
(\%)\end{array}$ & & \multicolumn{2}{l}{ Intends to circumcise daughter } \\
\cline { 5 - 5 } & & & Yes (\%) & No \\
\hline $\begin{array}{l}\text { Individual level } \\
\text { Education }\end{array}$ & 4895 & 74.8 & 93.3 & 6.7 \\
$\quad$ No Education & 845 & 12.9 & 88.6 & 11.4 \\
Primary & 712 & 10.9 & 74.2 & 25.8 \\
Secondary & 91 & 1.4 & 32.4 & 67.7 \\
Higher & & & &
\end{tabular}

\section{Age}

$15-19$
$20-24$
$25-29$
$30-34$
$35-39$
$40-44$
$45-49$

\section{Wealth}

Poorest

Poorer

Middle

Richer

Richest

\section{Religion}

Christianity

Islam

Other

\section{Healthcare decision}

Alone

With partner

Partner

Other

Number of daughters

0
1
2
3
4 or more

\section{Daughters Circumcised}

None

1

2

3 or More

Frequency of reading Newspaper
203

815

1490

1443

1367

687

538

1488

1426

1415

1221

993

1138

5390

15

539

2993

2982

29

3.1
12.5
22.8
22.0
20.9
10.5
8.2

8.2

22.7

21.8

21.6

18.7

15.2

17.4

82.4

0.2

8.2

45.7

45.5

0.4

854

3132

1746

625

186

5129

821

410

183

6263

103
2.9

78.4

12.5

6.3

2.8

13.1

47.9

26.7

6

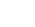

95.7

1.6
87.6

89.8

90.1

90.2

89.0

90.4

87.3

94.9

93.1

93.2

90.5

70.7

75.3

92.8

86.7

89.8

87.9

91.3

83.3

85.8

87.8

92.6

93.9

92.7

Not at all

Less than once a week
No (\%)

$X^{2}, \boldsymbol{p}$-value

618.048, $p<0.001$

6.7

11.4

25.8

67.7

12.4

$5.107,0.530$

10.2

9.9

9.8

11.0

9.6

12.7

5.2

460.818, $p<0.001$

6.9

6.8

9.5

29.3

322.448, $p<0.001$

24.7

7.2

13.3

19.549, $p<0.001$

10.2

12.1

8.7

16.7

54.180, $p<0.001$

14.2

12.2

7.4

6.1

7.3

115.497, $p<0.001$

12.5

2.8

2.4

1.1

411.951, $p<0.001$
8.7

40.2 
Table 1 Summary of socio-demographic characteristics of sample $(N=6543)$ (Continued)

\begin{tabular}{|c|c|c|c|c|c|}
\hline \multirow[t]{2}{*}{ Variable } & \multirow{2}{*}{$\begin{array}{l}\text { Weighted } \\
\text { Frequency } \\
\text { (n) }\end{array}$} & \multirow{2}{*}{$\begin{array}{l}\text { Percentage } \\
(\%)\end{array}$} & \multicolumn{2}{|c|}{ Intends to circumcise daughter in future } & \multirow[t]{2}{*}{$x^{2}, p$-value } \\
\hline & & & Yes (\%) & No (\%) & \\
\hline At least once a week & 177 & 2.7 & 52.3 & 47.7 & \\
\hline Frequency of listening to Radio & & & & & $60.484, p<0.001$ \\
\hline Not at all & 2813 & 43.0 & 92.2 & 7.8 & \\
\hline Less than once a week & 1428 & 21.8 & 90.7 & 9.3 & \\
\hline At least once a week & 2302 & 35.2 & 85.7 & 14.3 & \\
\hline Frequency of watching TV & & & & & $296.693, p<0.001$ \\
\hline Not at all & 5732 & 87.6 & 91.9 & 8.1 & \\
\hline Less than once a week & 292 & 4.5 & 83.7 & 16.3 & \\
\hline At least once a week & 519 & 7.9 & 68.5 & 31.5 & \\
\hline \multicolumn{6}{|l|}{ Contextual level } \\
\hline Family head & & & & & $9.217, p<0.01$ \\
\hline Male & 5176 & 79.1 & 90.2 & 9.8 & \\
\hline Female & 1366 & 20.9 & 87.5 & 12.5 & \\
\hline Region & & & & & $391.544, p<0.001$ \\
\hline Eastern & 1674 & 25.6 & 91.0 & 9.0 & \\
\hline Northern & 2515 & 38.4 & 93.6 & 6.4 & \\
\hline Southern & 1529 & 23.4 & 91.2 & 8.8 & \\
\hline Western & 825 & 12.6 & 68.8 & 31.2 & \\
\hline Residence & & & & & $248.236, p<0.001$ \\
\hline Rural & 1661 & 25.4 & 80.6 & 19.4 & \\
\hline Urban & 4882 & 74.6 & 93.5 & 6.5 & \\
\hline
\end{tabular}

Source 2013 Sierra Leone Demographic and Health Survey

All models revealed remarkable variation in FGM/C intention with respect to contextual factors. The empty model revealed VPC of $33.4 \%$, indicating that the variance in the likelihood of FGM/C intention is substantially attributable to contextual factors. The results for the MOR reflected same with $3.1 \%$ [2.7-3.4]. From the final model (model 4), when a woman relocates to a different contextual setting that has a higher probability of FGM/C intention, she stands $2.0 \%$ [1.7-2.2] increased chance of FGM/C intention for daughter. Similarly, the final model revealed that contextual factors account for $63.3 \%$ of FGM/ $\mathrm{C}$ intention for daughters. The variance inflation factor (VIF) test revealed that the independent variables were not highly correlated $($ mean $=1.31$, highest $=1.81$, least $=1.06)$.

\section{Discussion}

In this paper, we investigated whether educated women intend to circumcise their daughters in Sierra Leone. This study revealed that women who had no formal education were more than 4 times likely to report intention of subjecting their daughters to $\mathrm{FGM} / \mathrm{C}$ in the future compared to those with higher education. This result is consistent with community-based study on the change of practice of FGM/C in a Sudanese village where it was demonstrated that the level of education of the woman plays an important role in her decision or attitude towards the practice [44].

This finding is also consistent with the report by Asekun-Olarinmoye and Amusan [45] from their intervention study using a multistage sampling technique in a rural Nigerian community that reported that participants with no formal education were more likely to accept and engage in FGM/C. Formal education exposes people to harmful health practises, risky behaviours and human rights and as such could explain why participants with some level of formal education were not willing to subject their daughters to FGM/C. However, this finding does not support the findings of Allam et al. [46] from their cross sectional study involving university students in Egypt on FGM/C which reports that a considerable amount of educated populace in Egypt including university students, doctors and midwives were ignorant about FGM/C. It is therefore difficult in some situations to assume that formal education equates exposure to issues surrounding FGM/C.

It was found that poorer women were more likely to intend to expose their daughters to FGM/C than those who were rich. This finding is consistent with a Sudanese study 
Table 2 Individual and contextual factors associated with FGM/C intention for daughter in the future

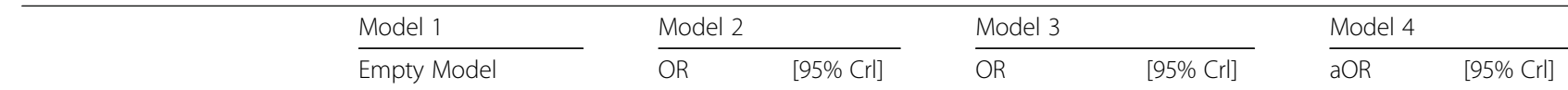

\section{Fixed-effects}

Individual level

\section{Education}

\begin{tabular}{|c|c|c|c|}
\hline No Education & $3.9^{* * *}$ & {$[2.1-7.0]$} & $4.3^{* * *}$ \\
\hline Primary & $2.9^{* * *}$ & [1.6-5.3] & $3.3^{* * *}$ \\
\hline Secondary & $2.0^{* *}$ & {$[1.1-3.3]$} & $2.2^{* *}$ \\
\hline Higher & 1 & [1] & 1 \\
\hline
\end{tabular}

\section{Age}

$15-19$
$20-24$
$25-29$
$30-34$
$35-39$
$40-44$
$45-49$

$\begin{array}{ll}1.9^{*} & {[1.1-3.3]} \\ 2.4^{* * *} & {[1.6-3.6]} \\ 2.2^{* * *} & {[1.5-3.3]} \\ 1.9^{* *} & {[1.3-2.8]} \\ 1.6^{* *} & {[1.1-2.4]} \\ 1.7^{*} & {[1.1-2.6]} \\ 1 & {[1]}\end{array}$

20-24

25-29

30-34

35-39

45-49

[1]

$2.3^{* * *} \quad[1.5-3.4]$

$2.2^{* * *} \quad[1.5-3.2]$

$1.8^{* *} \quad[1.3-2.7]$

$1.6^{*} \quad[1.1-2.3]$

$1.6^{*} \quad[1.1-2.5]$

Wealth

$\begin{array}{lll}\text { Poorest } & 3.3^{* * *} & {[2.3-4.7]} \\ \text { Poorer } & 2.3^{* * *} & {[1.6-3.2]} \\ \text { Middle } & 2.6^{* * *} & {[1.9-3.6]} \\ \text { Richer } & 1.9^{* * *} & {[1.4-2.6]} \\ \text { Richest } & 1 & {[1]}\end{array}$

Religion

Christianity

Islam

Other

Healthcare decision

Alone
With partner
Partner
Other

\section{Number of daughters}

1

2

3

4 or more

\section{Daughters Circumcised}

None
2
3 or More

\section{Frequency of reading Newspaper}

Not at all

$\begin{array}{ll}0.9 & {[0.2-4.4]} \\ 2.8 & {[0.6-12.7]} \\ 1 & {[1]}\end{array}$

$1.7 \quad[0.6-4.9]$

$1.6 \quad[0.6-4.6]$

$1.9 \quad[0.7-5.5]$

1 [1]

$\begin{array}{ll}0.97 & {[0.51-1.86]} \\ 1.25 & {[0.67-2.33]} \\ 1.80 & {[0.95-3.40]} \\ 1.59 & {[0.79-3.17]}\end{array}$

[0.79-3.17]

$\begin{array}{ll}2.1^{* *} & {[1.3-3.2]} \\ 1.4 & {[0.9-2.2]} \\ 1.7^{* *} & {[1.1-2.5]} \\ 1.5^{*} & {[1.1-2.0]} \\ 1 & {[1]}\end{array}$

1.0

[0.2-4.7]

$2.9 \quad[0.6-13.7]$

1 [1]

$\begin{array}{ll}1.7 & {[0.6-5.3]} \\ 1.7 & {[0.6-4.8]} \\ 1 & {[1]}\end{array}$

$0.99 \quad[0.52-1.91]$

1.27 [0.68-2.37]

1.82 [0.67-2.37]

$1.62 \quad[0.81-3.26]$

$\begin{array}{llll}0.1^{* * *} & {[0.0-0.3]} & 0.1^{* *} & {[0.0-0.3]} \\ 0.4 & {[0.1-1.6]} & 0.4 & {[0.1-1.7]} \\ 0.4 & {[0.1-2.1]} & 0.5 & {[0.1-2.2]} \\ 1 & {[1]} & 1 & {[1]}\end{array}$

$1.6^{*} \quad[1.1-2.5]$

$1.6 \quad[0.9-2.5]$ 
Table 2 Individual and contextual factors associated with FGM/C intention for daughter in the future (Continued)

\begin{tabular}{|c|c|c|c|c|c|c|c|c|}
\hline & \multicolumn{2}{|c|}{ Model 1} & \multicolumn{2}{|c|}{ Model 2} & \multicolumn{2}{|l|}{ Model 3} & \multicolumn{2}{|c|}{ Model 4} \\
\hline & \multicolumn{2}{|c|}{ Empty Model } & OR & {$[95 \% \mathrm{Crl}]$} & $\mathrm{OR}$ & {$[95 \% \mathrm{Crl}]$} & $\overline{\mathrm{aOR}}$ & {$[95 \% \mathrm{Crl}]$} \\
\hline \multicolumn{3}{|l|}{ Less than once a week } & 0.9 & {$[0.5-1.5]$} & & & 0.8 & {$[0.5-1.5]$} \\
\hline \multicolumn{3}{|l|}{ At least once a week } & 1 & {$[1]$} & & & 1 & {$[1]$} \\
\hline \multicolumn{9}{|c|}{ Frequency of listening to Radio } \\
\hline \multicolumn{3}{|l|}{ Not at all } & 0.9 & {$[0.8-1.2]$} & & & 0.9 & {$[0.8-1.2]$} \\
\hline \multicolumn{3}{|l|}{ Less than once a week } & 1.3 & {$[0.9-1.6]$} & & & 1.3 & {$[0.9-1.7]$} \\
\hline \multicolumn{3}{|l|}{ At least once a week } & 1 & [1] & & & 1 & {$[1]$} \\
\hline \multicolumn{9}{|l|}{ Frequency of watching TV } \\
\hline \multicolumn{3}{|l|}{ Not at all } & $1.4^{*}$ & {$[1.1-1.9]$} & & & 1.2 & {$[0.9-1.7]$} \\
\hline \multicolumn{3}{|l|}{ Less than once a week } & 1.2 & {$[0.7-1.8]$} & & & 1.1 & {$[0.72-1.7]$} \\
\hline \multicolumn{3}{|l|}{ At least once a week } & 1 & [1] & & & 1 & {$[1]$} \\
\hline \multicolumn{9}{|l|}{ Contextual level } \\
\hline \multicolumn{9}{|l|}{ Family head } \\
\hline \multicolumn{3}{|l|}{ Male } & & & 1.0 & {$[0.8-1.3]$} & 1.0 & {$[0.8-1.3]$} \\
\hline \multicolumn{3}{|l|}{ Female } & & & 1 & {$[1]$} & 1 & {$[1]$} \\
\hline \multicolumn{9}{|l|}{ Region } \\
\hline \multicolumn{3}{|l|}{ Eastern } & & & $3.4^{* * *}$ & {$[2.3-4.9]$} & $2.1^{* * *}$ & [1.4-3.1] \\
\hline \multicolumn{3}{|l|}{ Northern } & & & $4.3^{* * *}$ & {$[2.3-6.2]$} & $2.2^{* * *}$ & {$[1.5-3.2]$} \\
\hline \multicolumn{3}{|l|}{ Southern } & & & $3.1^{* * *}$ & {$[2.1-4.5]$} & $2.1^{* * *}$ & [1.4-3.1] \\
\hline \multicolumn{3}{|l|}{ Western } & & & 1 & {$[1]$} & 1 & {$[1]$} \\
\hline \multicolumn{9}{|l|}{ Residence } \\
\hline \multicolumn{3}{|l|}{ Rural } & & & $0.4^{* * *}$ & {$[0.3-0.6]$} & 0.8 & {$[0.6-1.1]$} \\
\hline \multicolumn{3}{|l|}{ Urban } & & & 1 & {$[1]$} & 1 & [1] \\
\hline \multicolumn{9}{|l|}{ Random-effects } \\
\hline Contextual level & & & & & & & & \\
\hline Variance (95\% Crl) & 1.4 & {$[1.11-1.7]$} & 0.6 & {$[0.4-0.7]$} & 0.7 & {$[0.5-0.9]$} & 0.51 & {$[0.3-0.7]$} \\
\hline VPC \%(95\% Crl) & 33.4 & [25.4-39.8] & 20.7 & [13.2-25.9] & 23.5 & [15.4-28.3] & 19.4 & {$[9.1-27.7]$} \\
\hline MOR $(95 \% \mathrm{Crl})$ & 3.1 & {$[2.7-3.4]$} & 2.0 & {$[1.8-2.3]$} & 2.2 & {$[2.0-2.5]$} & 2.0 & {$[1.7-2.2]$} \\
\hline Explained variation (\%) & 1 & {$[1]$} & 60.4 & {$[55.4-64.0]$} & 49.6 & {$[46.4-55.0]$} & 63.3 & {$[57.8-71.2]$} \\
\hline Sample Size & & & & & & & & \\
\hline Contextual level & & 435 & 435 & & 435 & & 435 & \\
\hline Individual level & & 6543 & 6543 & & 6543 & & 6543 & \\
\hline
\end{tabular}

$a O R$ adjusted Odds Ratio, OR Odds Ratio, $\mathrm{Crl}$ Credible Interval, VPC Variance Partition Coefficient:

MOR Median Odds Ratio; 1 = reference; $\left.{ }^{*} p<0.05,{ }^{* *} p<0.01,{ }^{* * *} p<0.001\right]$

Source 2013 Sierra Leone Demographic and Health Survey

which reported high prevalence of FGM/C among the poor [47]. Poverty limits ones access to education and as such could be a major hindrance for such women to be either exposed to the harmful effects of FGM/C or to learn about it. Poverty sometimes puts enormous pressure on daughters' marriageability, since their sustenance may depend on good marriage. If men embrace such practice and prefer to marry females who have been circumcised, women may feel obliged to circumcise their daughters. Consequently, educating men and boys about the demerits of FGM/C, in addition to females, can expedite the abandonment process of FGM/C because men have a significant role to play [48].

Region and residence of the respondents also played an important role. A significant proportion of women who were residents of rural settings intended to circumcise their daughters in the future. This is consistent with the findings of Alo and Gbadebo [49] from their study on intergenerational attitude changes regarding FGM/ $\mathrm{C}$ in Nigeria that showed that females in a rural setting were more likely to support FGM/C compared to those living in urbanised communities. This is expected 
considering the fact that most women who find themselves in the rural areas are accustomed to tradition, have low levels of education and have little or no access to information and media as compared to those who live in urban areas. With more development programs in urban areas, it is likely for urban residents to have exposure to or receive health education and information on the harmful effects of the practice for informed decision making on whether or not to allow their daughters to be circumcised.

Comparing women aged 45-49 to those aged 15-19 and those within 20-24 age bracket, the 15-19 and 2024 age brackets were thrice more probable to indicate that they intend to circumcise their daughters in the future. This is an indication that the younger women were more likely to circumcise their daughters in the future compared with their older counterparts. The older counterparts could be exposed to more education on the effects of FGM/C and as such can make more informed decisions and choices for their daughters as compared with their younger counterparts. This is consistent with the account of Rahlenbeck and Mekonnen [50]. They indicated that lower age categories were associated with increased odds of FGM/C among women. This finding is however in variance with the findings from a study conducted by Alo and Gbadebo [51] in South Western Nigeria where they noted that older respondents were more likely to accept FGM/C as compared to their younger respondents. The assumption is that younger respondents were more likely to be educated which will increase their chances of engaging with FGM/C education and their associated harmful effects, thereby influencing their decisions.

Women who do not read newspapers at all were more likely to indicate that they intend to circumcise their daughters in the future compared with women who read newspapers at least once a day. This can be attributed to the fact that women who read newspapers are more exposed and informed about issues surrounding human rights and harmful health practises. They are more likely to know and understand negative effects of FGM/C. Malhotra et al. [52] mentioned that women who read are more likely to weigh the benefits over the risks before making decisions about their health. A clear understanding of the benefits of not circumcising is likely to be attractive to women. In addition, when women are able to make autonomous decisions, they are able to take actions that will favour them [53].

The study revealed that contextual factors account for women's FGM/C intention in Sierra Leone. This implies that FGM/C intention transcends beyond the individual or personal level factors. This finding is consistent with reports by the UNFPA and other Sierra Leone based FGM/C studies $[6,54,55]$. As such, there is the need for the government and anti-FGM/C institutions in Sierra Leone to focus on wider social norms. This is needful because contextual factors may greatly condition the impact of maternal education on women's FGM/C intention [56].

Due to the cross-sectional study design, our results do not lend itself to causal inference. There is also the possibility of under or over reporting based on the women's evaluation of how society expects them to react to FGM/ C. The data supporting this study emerged from a survey conducted in 2013, though remains the most current of the DHS in Sierra Leone as of now. As a result, this may not reflect the current phenomenon, however, it presents an accurate findings of nationwide coverage which can direct FGM/C policies. This study involves a nationally representative sample which can be generalised not only to Sierra Leone but other low and middle income countries in Africa.

\section{Conclusion}

Women with low levels of education are more probable to circumcise their daughters in the future. Poor women also have high FGM/C inclination. Formal education is essential and critical to stopping FGM/C in Sierra Leone. Efforts to reduce FGM/C among women requires a strategy that will focus attention on strengthening and enforcing the existing laws on FGM/C as well as formulating policies that will reduce poverty among rural women especially women in the rural Sierra Leone where the practice is endemic. Pro female child education policies must also be introduced to achieve the desired set targets.

\section{Abbreviations}

AOR: Adjusted Odds Ratio; Cl: Confidence Interval; Crl: Credible Interval; EA: Enumeration Area; FGM/C: Female genital mutilation/cutting; FC: Female circumcision; MOR: Median Odds Ratio; MoU: Memorandum of Understanding; OR: Odds Ratio; PSU: Primary Sampling Units; SLDHS: Sierra Leone Demographic and Health Survey; SSL: Statistics Sierra Leone; TV: Television; VPC: Variance Partition Coefficient; WHO: World Health Organisation

\section{Acknowledgments \\ The authors would like to thank Measure DHS for giving us access to the data.}

\section{Authors' contributions}

EKA and AS developed the concept of the study, JKT performed the discussion, EKA-A drafted the background, AS drafted the methodology. EKA and KAA performed the analysis and KAA wrote the abstract. All authors proofread and approved the manuscript for submission.

\section{Funding}

Not applicable.

\section{Availability of data and materials}

The datasets supporting the conclusions of this article are available in the Measure DHS repository, https://dhsprogram.com/data/available-datasets.cfm. 


\section{Ethics approval and consent to participate}

Ethical approval was granted by the Ministry of Health and Sanitation of Sierra Leone as well as the ethics committee of the DHS Program. During the survey, informed consent was sought from all participants. We applied for and granted permission to the dataset from the Measure DHS Program. The dataset is freely available through https://dhsprogram.com/data/ available-datasets.cfm.

\section{Consent for publication}

Not applicable.

\section{Competing interests}

The authors have declared there is no computing interest.

\section{Author details}

${ }^{1}$ The Australian Centre for Public and Population Health Research, Faculty of Health, University of Technology Sydney, Sydney, NSW, Australia. ${ }^{2}$ Department of Population and Health, College of Humanities and Legal Studies, University of Cape Coast, Cape Coast, Ghana. ${ }^{3}$ Centre for Health Services Management, Faculty of Health, University of Technology Sydney, Sydney, NSW, Australia. ${ }^{4}$ Nursing and Midwifery Training College, Sunyani, Ghana.

Received: 9 March 2020 Accepted: 15 July 2020

Published online: 23 July 2020

\section{References}

1. United Nations. Transforming our world: the 2030 agenda for sustainable development. Geneva: United Nations; 2015.

2. Nabaneh S, Muula AS. Female genital mutilation/cutting in Africa: A complex legal and ethical landscape. Int Federation Gynecol Obstetr. 2019; 145:253-7.

3. World Bank. Compendium of international and national legal frameworks on female genital mutilation. Washington DC: World Bank; 2018.

4. Olaniran AO. The relationship between female genital mutilation and transmission in sub-Saharan Africa. Afr J Reprod Health. 2017;17(4):156-60.

5. UNFPA. Female genital mutilation (FGM) frequently asked questions; 2019. Retrieved from https://www.unfpa.org/resources/female-genital-mutilationfgm-frequently-asked-questions on May 28, 2020

6. Bjälkander O, Grant DS, Berggren V, Bathija H, Almroth L. Female genital mutilation in Sierra Leone: forms, reliability of reported status, and accuracy of related demographic and health survey questions. Obstet Gynecol Int. 2013:2013:1-15.

7. WHO. Female genital mutilation; 2020. Retrieved from https://www.who.int/ news-room/fact-sheets/detail/female-genital-mutilation on May 26, 2020.

8. WHO. FGM Fact Sheet. WHO: 2018. Accessed from https://www.who.int/en/ news-room/fact-sheets/detail/female-genital-mutilation on August 15, 2019.

9. Koski A, Heymann J. Thirty-year trends in the prevalence and severity of female genital mutilation: a comparison of 22 countries. BMJ Glob Health. 2017;2:e000467

10. UNICEF. Female genital mutilation/cutting: A global concern. New York: UNICEF; 2016. Accessed from www.unicef.org/media/files/FGMC_2016_ brochure_final_UNICEF_SPREAD.pdf. A on September 30, 2019.

11. Yoder P, Abderrahim N, Zhuzhuni A. Female genital cutting in the demographic and health surveys: a critical and comparative analysis. DHS comparative reports no 7. Calverton: Macro International; 2004.

12. Almroth L, Bedri H, El Elmusharaf S, Satti A, Idris T, Hashim MSK, et al. Urogenital complications among girls with genital mutilation: A hospital based study in Khartoum. Afr J Reprod Health. 2005;9:127-33.

13. World Health Organization. Eliminating female genital mutilation. An interagency statement. Geneva: World Health Organization; 2008. Accessed from http://www.who.int/reproductivehealth/publications/fgm/97892415 96442/en/ on June 1, 2018

14. Talle A. Female circumcision in Africa and beyond: the anthropology of a difficult issue. In: Hernlund Y, Shell-Duncan B, editors. Transcultural bodies: female genital cutting in global context. New Brunswick: Rutgers University Press; 2007. p. 91-106.

15. Bjälkander $O$, Bangura L, Leigh B, Berggren V, Bergström S, Almroth L. Health complications of female genital mutilation in Sierra Leone. Int $J$ Women's Health. 2012;4:321-31.
16. Shell-Duncan B, Naik R, Feldman-Jacobs C. A state-of-the-art synthesis on female genital mutilation/cutting: what do we know now? October 2016. New York: Population Council; 2016. Accessed from http://www.popcouncil. org/EvidencetoEndFGM-C on August 12, 2019.

17. Rymer J. Female genital mutilation: everyone's problem. Br J Gen Pract. 2013;63:515-6.

18. Mpofu S, Odimegwu C, De Wet N, et al. The relation of female circumcision to sexual behavior in Kenya and Nigeria. Women Health. 2016;2016:1-18.

19. Sakeah E, Debpuur C, Aborigo RA, Oduro AR, Sakeah JK, Moyer CA. Persistent female genital mutilation despite its illegality: Narratives from women and men in northern Ghana. PloS One. 2019;14(4):1-14.

20. Abathun AD, Sundby J, Gele AA. Attitude toward female genital mutilation among Somali and Harari people, Eastern Ethiopia. Int J Women's Health. 2016;8:557.

21. Yount KM. Symbolic gender politics, religious group identity, and the decline in female genital cutting in Minya, Egypt. Social Forces. 2004;82(3):1063-90.

22. UNICEF. Female genital mutilation/cutting: a statistical overview and exploration of the dynamics of change. New York: UNICEF; 2013.

23. Unicef-IRC. The Dynamics of Social Change Towards the Abandonment of Female Genital Mutilation/Cutting in Five African Countries. Florence: UNICEF; 2010

24. Odukogbe AA, Afolabi BB, Bello OO, Adeyanju AS. Female genital mutilation/cutting in Africa. Transl Androl Urol. 2017;6(2):138-48.

25. McCauley M, Van De Broek N. Challenges in the eradication of female genital mutilation/cutting. Int Health. 2019;11:1-4.

26. Van Rossem R, Meekers D, Gage AJ. Women's position and attitudes towards female genital mutilation in Egypt: A secondary analysis of the Egypt demographic and health surveys, 1995-2014. BMC Public Health. 2015;15(1):874.

27. Farina P, Ortensi LE. Mother to daughter transmission of female genital cutting in Egypt, Burkina Faso and Senegal. Afr Popul Stud. 2014;6(28):1119-31.

28. Grose RG, Hayford SR, Cheong YF, Garver S, Kandala NB, Yount KM. Community influences on female genital mutilation/cutting in Kenya: norms, opportunities, and ethnic diversity. J Health Soc Behav. 2019;60(1):84-100.

29. Sakeah E, Debpuur C, Oduro AR, Welaga P, Aborigo R, Sakeah KJ, Moyer CA. Prevalence and factors associated with female genital mutilation among women of reproductive age in the Bawku municipality and Pusiga District of northern Ghana. BMC Womens Health. 2018;18:150.

30. Yount KM, Cheong YF, Grose RG, Hayford SR. Community gender systems and a daughter's risk of female genital mutilation/cutting: Multilevel findings from Egypt. Plos One. 2020;15(3):e0229917.

31. Grose RG, Roof KA, Semenza DC, Leroux X, Yount KM. Mental health, empowerment, and violence against young women in lower-income countries: A review of reviews. Aggress Violent Behav. 2019;1(46):25-36.

32. Yount KM. Like mother, like daughter? Female genital cutting in Minia, Egypt. J Health Soc Behav. 2002;1:336-58.

33. Hayford SR, Garver S, Soura AB, Cheong YF, Grose RG, Yount KM. Community influences on female genital mutilation/cutting: A comparison of four francophone west African countries. Stud Fam Plan. 2020;51(1):3-2.

34. Bjalkander O, Leigh B, Harman G, Bergstrom S, Almroth L. Female genital mutilation in Sierra Leone: who are the decision makers? Africa J Reprod Health. 2012;16(4):35-46.

35. Behrendt A. Female genital cutting in the Moyamba and Bombali districts of Sierra Leone. Plan West Africa Regional Office: Dakar, Sierra Leone; 2005.

36. Wilson AM. Country profile: FGM in Sierra Leone; 2014.

37. Fanthorpe R. Sierra Leone: the influence of the secret societies, with special reference to female genital mutilation, commission by the UN high commissioner for refugees. WriteNet; 2007.

38. Statistics Sierra Leone (SSL) and ICF International. Sierra Leone demographic and health survey 2013. Freetown, Sierra Leone and Rockville, Maryland: SSL and ICF International; 2014

39. Rasbash J, Charlton C, Browne WJ, Healy M, Cameron B. MLwiN version 2.31. Bristol: University of Bristol, Centre for Multilevel Modelling; 2014.

40. Curran JM. An introduction to Bayesian credible intervals for sampling error in DNA profiles. Law, Probability and Risk. 2005;1:4(1-2):115-26.

41. Larsen K, Merlo J. Appropriate assessment of neighborhood effects on individual health: integrating random and fixed effects in multilevel logistic regression. Am J Epidemiol. 2005;161(1):81-8.

42. Merlo J, Chaix B, Yang M, Lynch J, Råstam L. A brief conceptual tutorial of multilevel analysis in social epidemiology: linking the statistical concept of clustering to the idea of contextual phenomenon. J Epidemiol Commun Health. 2005;59(6):443-9. 
43. Akinwande MO, Dikko HG, Samson A. Variance inflation factor: as a condition for the inclusion of suppressor variable (s) in regression analysis. Open J Stat. 2015;5(07):754

44. Almroth L. Genital mutilation of girls in Sudan: community-and hospitalbased studies on female genital cutting and its sequelae. Stockholm: Institutionen för folkhälsovetenskap/Department of Public Health Sciences; 2005.

45. Asekun-Olarinmoye EO, Amusan OA. The impact of health education on attitudes towards female genital mutilation (FGM) in a rural Nigerian community. Eur J Contracept Reprod Health Care. 2008;13(3):289-97.

46. Allam MF, De Irala-Estevez J, Navajas RFC, del Castillo AS, Hoashi JS, Pankovich $M B$, Liceaga JR. Factors associated with the condoning of female genital mutilation among university students. Public Health. 2001;115(5):350-5.

47. Elduma AH. Female Genital Mutilation in Sudan. Open Access Maced J Med Sci. 2018:6(2):430-4.

48. Varol N, Turkmani S, Black K, Hall J, Dawson A. The role of men in abandonment of female genital mutilation: a systematic review. BMC Public Health. 2015 Dec;15(1):1034.

49. Setegn T, Lakew Y, Deribe K. Geographic variation and factors associated with female genital mutilation among reproductive age women in Ethiopia: a national population based survey. PloS One. 2016;11(1):e0145329.

50. Rahlenbeck SI, Mekonnen W. Growing rejection of female genital cutting among women of reproductive age in Amhara, Ethiopia. Cult Health Sex. 2009;11(4):443-52.

51. Alo OA, Gbadebo B. Intergenerational attitude changes regarding female genital cutting in Nigeria. J Women's Health. 2011;20(11):1655-61.

52. Malhotra A, Pande R, Grown C. Impact of Investments in Female Education on Gender Equality; 2003. Accessed from http://siteresources.worldbank.org/ INTGENDER/Resources/ImpactlnvestmentsFemaleEdu.pdf on 15 Aug 2019.

53. Adhikari R. Effect of Women's autonomy on maternal health service utilization in Nepal: a cross sectional study. BMC Womens Health. 2016;16:26.

54. UNFPA. International Day of Zero Tolerance to Female Genital Mutilation: Ending FGM is a political decision; 2018. Retrieved from https://sierraleone. unfpa.org/en/news/international-day-zero-tolerance-female-genitalmutilation-ending-fgm-political-decision on 30th May, 2020.

55. Ibrahim AF. The Bondo society as a political tool: examining cultural expertise in Sierra Leone from 1961 to 2018. Laws. 2019:8(3):17.

56. Shell-Duncan B, Moreau A, Wander K, Smith S. The role of older women in contesting norms associated with female genital mutilation/cutting in Senegambia: A factorial focus group analysis. PloS one. 2018;13(7):1-19.

\section{Publisher's Note}

Springer Nature remains neutral with regard to jurisdictional claims in published maps and institutional affiliations.

Ready to submit your research? Choose BMC and benefit from:

- fast, convenient online submission

- thorough peer review by experienced researchers in your field

- rapid publication on acceptance

- support for research data, including large and complex data types

- gold Open Access which fosters wider collaboration and increased citations

- maximum visibility for your research: over $100 \mathrm{M}$ website views per year

At $\mathrm{BMC}$, research is always in progress.

Learn more biomedcentral.com/submissions 